\title{
Psychological Morbidity among People in Quarantine
}

\author{
Krishan Kumar ${ }^{1}$ Aseem Mehra ${ }^{1}$ Shweta Jha ${ }^{2}$ Rajni Sharma ${ }^{3} \quad$ Lokesh Saini $^{4}$ Swapnajeet Sahoo ${ }^{1}$ \\ P. V. M. Laxmi ${ }^{5}$ Ashish Bhalla ${ }^{6}$ Sandeep Grover ${ }^{1}$
}

\author{
${ }^{1}$ Department of Psychiatry, Postgraduate Institute of Medical \\ Education \& Research, Chandigarh, India \\ 2Department of Psychiatry, Amity Institute of Behavioural Health \\ and Allied Sciences, New Delhi, India \\ ${ }^{3}$ Department of Paediatrics, Advance Paediatric Centre, \\ Postgraduate Institute of Medical Education \& Research, \\ Chandigarh, India \\ ${ }^{4}$ Department of Paediatric, Postgraduate Institute of Medical \\ Education \& Research, Chandigarh, India \\ ${ }^{5}$ Department of Community Medicine, Postgraduate Institute of \\ Medical Education \& Research, Chandigarh, India \\ 6 Department of Internal Medicine, Postgraduate Institute of \\ Medical Education \& Research, Chandigarh, India
}

\begin{abstract}
Address for correspondence Sandeep Grover, MD, Department of Psychiatry, Postgraduate Institute of Medical Education \& Research, Chandigarh 160012, India (e-mail: drsandeepg2002@yahoo.com).
\end{abstract}

\author{
Abstract \\ Keywords \\ - COVID-19 \\ - psychological \\ morbidity \\ - quarantine
}

Objective This study aimed to evaluate psychological distress of persons in quarantine and compare the same with a group of persons, who are currently in lockdown. Methodology Forty-four persons in quarantine and 45 subjects currently in lockdown were evaluated on Depression Anxiety Stress Scale II.

Results About three-fourth (77.3\%) of the participants in the quarantine group and one-third (37.8\%) in the comparator group had depression. About one fourth (22.7\%) in the quarantine group and one-third (35.6\%) in the lockdown group had anxiety. Conclusion The present study suggests that lockdown and being in quarantine are associated with significantly higher psychiatric morbidity, especially anxiety.

\section{Introduction}

In the past two decades, several epidemics such as severe acute respiratory syndrome and Middle-East respiratory syndrome that emerged as threat to public life and were associated with psychological morbidity. ${ }^{1-4}$ Currently, coronavirus disease 2019 (COVID-19) reported being a serious threat to people's physical and psychological health. It is expected to be associated with more physical and psychological problems because of being highly contagious with the possibility of causing severe respiratory disease, and an understanding of its adverse effects on the human psyche; on March 11, 2020, it was declared as a worldwide pandemic (WHO, 2020). ${ }^{5}$ COVID-19 has affected 213 countries with a more than 14,348,858 lakh confirmed cases and 603,691 confirmed death. Extraordinary measures have been taken to prevent the contagion and limit its outbreak. However, available reports suggest that COVID-19 pandemic has affected the lives of millions of people, and has led to a global, multilevel, and demanding stress-coping-adjustment process. India has taken relentless measure as an effort to overcome this pandemic and imposed lockdown since March 25, 2020, in fighting the pandemic. A wide fragment of world's population is primarily restricted to their homes, owing to nationwide lockdowns, socially disconnected from society, colleagues, workplace, and even extended family members. This certainly has added to the stress, burden, and has affected the quality of life of every individual. COVID-19 has a substantial psychological impact on every individual's life and has undoubtedly changed the way we live. ${ }^{6}$ In such a situation, understanding the psychological manifestation of such crisis on human being becomes the primal concern for the mental health professional. There are a few numbers of studies which evaluated the impact of quarantine on mental health. All the studies reported a higher rate of psychological distress among the quarantined people in comparison to those who were not quarantined. ${ }^{6}$ The studies
DOI https://doi.org/ 10.1055/s-0040-1718855 ISSN 0976-3147.

\section{(C) 2021. Association for Helping Neurosurgical Sick People.}

This is an open access article published by Thieme under the terms of the Creative Commons Attribution-NonDerivative-NonCommercial-License, permitting copying and reproduction so long as the original work is given appropriate credit. Contents may not be used for commercial purposes, or adapted, remixed, transformed or built upon. (https://creativecommons.org/licenses/by-nc-nd/4.0/) Thieme Medical and Scientific Publishers Pvt. Ltd., A-12, 2nd Floor, Sector 2, Noida-201301 UP, India 
reported higher rate of psychological symptoms, ${ }^{7}$ emotional disturbance, ${ }^{8}$ depression, ${ }^{9}$ stress,${ }^{10}$ low mood, ${ }^{11}$ irritability, ${ }^{11}$ sleep disturbances, ${ }^{11}$ posttraumatic stress disorders, ${ }^{12}$ emotional exhaustion, ${ }^{13}$ and anger outbursts ${ }^{14}$; irritability ${ }^{11}$ and anxiety stand out as a higher prevalence. ${ }^{11}$ However, none of the study has evaluated the level of psychological morbidity among the people who were homebound due to lockdown in comparison with the quarantined people. Accordingly, the present study aimed to compare the psychological impact of self-quarantine and social isolation due to lockdown on adults during COVID-19 pandemic.

\section{Methodology}

The study included 89 participants recruited by purposive sampling, divided into two groups, that is, Group-I (44 subjects quarantined for suspected COVID-19 infection or due to having in close contact with persons with COVID-19 infection or having a travel history) and Group-II (45 subjects, who were homebound due to the lockdown). Approval from the ethical committee was sought before initiation of the study. Verbal and electronic consent (i.e., the participants were provided information about the study through WhatsApp and were asked to give their consent, whether they want to participate, by answering with "yes" or "no") were taken from participants prior to enrollment. Participants were given liberty to terminate their participation anytime they desired. The confidentiality of the information was assured and maintained. To be included in the study, the participants were required to be $\geq 18$ years of age and able to read English/Hindi. First, the participants were approached telephonically and explained about the survey. Those who agreed to participate and provided verbal consent were further sent the survey link generated by using
Google form. The survey was designed in such a way that one response could be possible with one mobile. Besides the basic demographic data, the participants were asked to complete the Depression Anxiety Stress Scale (DASS II). Assessments were done after $\sim 2$ weeks of quarantine. The survey was conducted from Mid-April to Mid-May.

Depression Anxiety Stress Scale (DASS II): This scale comprises 21 items. The scale has three subdomains including the depression (seven items), anxiety (seven items), and stress (seven items). The item of the scale is rated on a 4-point Likert scale from 0 to 3 (never a problem-almost always a problem). The higher the scale, the higher the level of depression, anxiety, and stress. The total score is calculated by summing the scores for each subscale. The severity of the scale is graded as normal (0-4 for depression, $0-3$ for anxiety, and $0-7$ for stress), mild (5-6 for depression, 4-5 for anxiety, and 8-9 for stress), moderate (7-10 for depression, 6-7 for anxiety, and 10-12 for stress), severe (11-13 for depression, 8-9 for anxiety, and 13-14 for stress), and extremely severe ( $>14$ for depression, $>10$ for anxiety, and $>17$ for stress $).{ }^{15}$

\section{Statistical Analysis}

Data were analyzed by using Statistical Package for Social Sciences, version 14 (SPSS-14) for Windows. Descriptive statistics, Pearson's correlation analysis and $t$-test, were used to analyze the data.

\section{Results}

The study sample comprised 44 people in quarantine group and 45 people in the control group, that is, homebound due to lockdown. The demographic profile of both the study groups is given in - Table $\mathbf{1}$.

Table 1 Sociodemographic profile of the study sample

\begin{tabular}{|c|c|c|c|}
\hline & $\begin{array}{l}\text { Group-I }(n=44) \\
\text { Frequency }(\%) / \\
\text { mean (SD) }\end{array}$ & $\begin{array}{l}\text { Group-II }(n=45) \\
\text { Frequency }(\%) / \text { mean }(S D)\end{array}$ & Chi-square/t-test ( $p$-value) \\
\hline \multicolumn{4}{|l|}{ Age group (y) } \\
\hline $24-31$ & $11(25.0 \%)$ & $30(66.7 \%)$ & \multirow[t]{3}{*}{$16.65(<0.001)$} \\
\hline $32-41$ & 21 (47.7\%) & 12 (26.7\%) & \\
\hline $41-48$ & $12(27.3 \%)$ & $3(6.7 \%)$ & \\
\hline Age (y) & $35.6(6.1)$ & $30.7(5.2)$ & $4.072(<0.001)$ \\
\hline \multicolumn{4}{|l|}{ Gender } \\
\hline Male & $22(50.0 \%)$ & 22 (48.9\%) & \multirow[t]{2}{*}{$0.011(0.917)$} \\
\hline Female & $22(50.0 \%)$ & $23(51.1 \%)$ & \\
\hline \multicolumn{4}{|l|}{ Education } \\
\hline Graduate & 24 (54.5\%) & $19(42.2 \%)$ & \multirow[t]{2}{*}{$1.353(0.245)$} \\
\hline Postgraduate & 20 (45.5\%) & $26(57.8 \%)$ & \\
\hline \multicolumn{4}{|l|}{ Marital status } \\
\hline Single & $10(22.7 \%)$ & 22 (48.9\%) & \multirow[t]{2}{*}{$6.612(0.10)$} \\
\hline Married & 34 (77.3\%) & $23(51.1 \%)$ & \\
\hline
\end{tabular}

Abbreviation: SD, standard deviation. 
Compared with the lockdown group, significantly higher proportion of the participants belonging to the quarantine group had depression, anxiety, and stress. Compared with the lockdown group, the mean scores for depression, anxiety, and stress were also higher for those belonging to the quarantine group (-Table 2).

\section{Discussion}

The psychological impact of the pandemic is being felt by everyone on the globe. The same is evident in the present study too. About three-fourth of those who were under quarantine and about one-third of those in the lockdown reported depression. In terms of anxiety, in the quarantine group, almost everyone (97.7\%) and about two-thirds of the participants in the lockdown group reported anxiety. In terms of severity, in the quarantine group, half of the participants reported at least a moderate level of depression, and $6.8 \%$ reported severe depression. In terms of anxiety, more than $90 \%$ reported at least a moderate level of anxiety, with $\sim 60 \%$ having severe to extremely severe anxiety. Higher prevalence of depression and anxiety among the participants under quarantine, when compared with those facing lockdown is supported by the existing literature. ${ }^{16-18}$ Further, when these prevalence rates for both groups are compared with the data reported for the National Mental Health Survey, ${ }^{19}$ it can be said that the prevalence rates among those under quarantine are significantly higher than the general population. These findings suggest that being under lockdown is also associated with adverse psychological outcome when compared with the normal situation. However, being in quarantine is much worse, psychologically. Socialization, responsibilities, and life expectations are few social factors that play a huge role in how we act or perceive a present situation in life. When these aspects of life are threatened or challenged, these can lead to significant emotional turmoil, as is evident from the present study. The higher prevalence of psychological morbidity can be attributed to the confinement at one place. Additional factors which possibly contribute to psychological distress include isolation, stigma, fear of unknown, and fear of death. ${ }^{18,20}$ Accordingly, there is a need to focus on the psychological needs of patients in quarantine and general public, who are facing lockdown. Besides, preparing for medical emergency, the Government should also plan to address the psychological needs of people. There is a need to develop, self-help groups, and counseling manuals which can be used by less trained people to address the psychological needs of the public at large. The present study was limited by the cross-sectional study design. The sample size was small. The other variables which can influence the findings, such as knowledge and attitude toward the COVID-19, social support, history of physical or psychological disorders in the past, cultural aspects, etc., were not evaluated. Future studies must attempt to overcome these limitations.

\section{Conclusion}

To conclude, the present study suggests that lockdown and being in quarantine are associated with significantly higher psychiatric morbidity, especially anxiety. The prevalence of depression is also significantly higher in both the groups, compared with that reported in earlier studies conducted among people from the general population. In terms of overall negative psychological impact, being in quarantine has significantly higher negative psychological impact compared with the lockdown situation. These findings suggest that

Table 2 Scores on Depression Anxiety Stress Scale

\begin{tabular}{|c|c|c|c|}
\hline Variables & Quarantine $(N=44)$ & Lockdown $(N=45)$ & Chi-square/t-test ( $p$-value) \\
\hline \multicolumn{4}{|l|}{ Depression } \\
\hline Normal & $10(22.7 \%)$ & $28(62.2 \%)$ & \multirow[t]{4}{*}{$33.479(<0.001)$} \\
\hline Mild & $9(20.5 \%)$ & $16(35.6 \%)$ & \\
\hline Moderate & $22(50 \%)$ & 0 & \\
\hline Severe & $3(6.8 \%)$ & $1(2.2 \%)$ & \\
\hline \multicolumn{4}{|l|}{ Depression } \\
\hline Present & $34(77.3)$ & $17(37.8)$ & \multirow[t]{2}{*}{$14.184(<0.001)$} \\
\hline Absent & $10(22.7)$ & $28(62.2)$ & \\
\hline Mean score & $13.7(5.1)$ & $8.6(3.4)$ & $5.591(<0.001)$ \\
\hline \multicolumn{4}{|l|}{ Anxiety } \\
\hline Normal & $1(2.3 \%)$ & $11(24.4 \%)$ & \multirow[t]{5}{*}{$18.113(0.001)$} \\
\hline Mild & $10(22.7 \%)$ & $11(24.4 \%)$ & \\
\hline Moderate & $19(43.2 \%)$ & $21(46.7 \%)$ & \\
\hline Severe & $12(27.3 \%)$ & $1(2.2 \%)$ & \\
\hline Extremely severe & $2(4.5 \%)$ & $1(2.2 \%)$ & \\
\hline Mean score & $22.7(5.7)$ & $18.8(5.6)$ & $3.244(0.002)$ \\
\hline Total score & $51.7(9.4)$ & $37.1(9.0)$ & $8.782(<0.001)$ \\
\hline
\end{tabular}


there is a need to develop large-scale psychological intervention services for people facing quarantine and the lockdown.

\section{Conflict of Interest}

None declared.

\section{References}

1 Mental health and psychosocial considerations during the COVID-19 outbreak. Available at: https://www.who.int/docs/ defaultsource/coronaviruse/mental-health-considerations. pdf. Accessed March 18, 2020

2 Centers for Disease Control and Prevention. Interim U.S. guidance for risk assessment and public health management of health care personnel with potential exposure in a health care setting to patients with 2019 novel coronavirus (2019-nCoV). 2020

3 Emergency Responders. Tips for taking care of yourself; centre of disease control and prevention. Available at: https://emergency.cdc.gov/coping/responders.asp. Accessed June 16, 2020

4 Interim Briefing Note Addressing Mental Health and Psychosocial Aspects of COVID-19 Outbreak (developed by the IASC's Reference Group on Mental Health and Psychosocial Support). Available at: https://interagencystandingcommittee. org/iasc-reference-group-mental-health-andpsychosocial-support-emergency-settings/interim-briefing. Accessed June 16, 2020

5 COVID-19 situation reports - World Health Organization (update on April 30, 2020). Available at: https://www.who. int/emergencies/diseases/novel-coronavirus-2019/situation-reports. Accessed April 30, 2020

6 Brooks SK, Webster RK, Smith LE, et al. The psychological impact of quarantine and how to reduce it: rapid review of the evidence. Lancet 2020;395(10227):912-920

7 Mihashi M, Otsubo Y, Yinjuan X, Nagatomi K, Hoshiko M, Ishitake T. Predictive factors of psychological disorder development during recovery following SARS outbreak. Health Psychol 2009;28(1):91-100

8 Yoon MK, Kim SY, Ko HS, Lee MS. System effectiveness of detection, brief intervention and refer to treatment for the people with post-traumatic emotional distress by MERS: a case report of community-based proactive intervention in South Korea. Int J Ment Health Syst 2016;10:51

9 Hawryluck L, Gold WL, Robinson S, Pogorski S, Galea S, Styra R. SARS control and psychological effects of quarantine, Toronto, Canada. Emerg Infect Dis 2004;10(7):1206-1212

10 DiGiovanni C, Conley J, Chiu D, Zaborski J. Factors influencing compliance with quarantine in Toronto during the 2003 SARS outbreak. Biosecur Bioterror 2004;2(4):265-272

11 Lee S, Chan LY, Chau AM, Kwok KP, Kleinman A. The experience of SARS-related stigma at Amoy Gardens. Soc Sci Med 2005;61(9):2038-2046

12 Reynolds DL, Garay JR, Deamond SL, Moran MK, Gold W, Styra R. Understanding, compliance and psychological impact of the SARS quarantine experience. Epidemiol Infect 2008;136(7):997-1007

13 Marjanovic Z, Greenglass ER, Coffey S. The relevance of psychosocial variables and working conditions in predicting nurses' coping strategies during the SARS crisis: an online questionnaire survey. Int J Nurs Stud 2007;44(6):991-998

14 Maunder R, Hunter J, Vincent L, et al. The immediate psychological and occupational impact of the 2003 SARS outbreak in a teaching hospital. CMAJ 2003;168(10):1245-1251

15 Lovibond SH, Lovibond PF, Manual for the Depression Anxiety Stress Scales. 2nd. ed. Sydney: Psychology Foundation; 1995

16 Abad C, Fearday A, Safdar N. Adverse effects of isolation in hospitalised patients: a systematic review. J Hosp Infect 2010;76(2):97-102

17 Johal SS. Psychosocial impacts of quarantine during disease outbreaks and interventions that may help to relieve strain. $\mathrm{N}$ Z Med J 2009;122(1296) :47-52

18 Grover S, Dua D, Sahoo S, Mehra A, Nehra R, Chakrabarti S. Why all COVID-19 hospitals should have mental health professionals: the importance of mental health in a worldwide crisis! Asian J Psychiatr 2020 51:102147

19 Gururaj G, Varghese M, Benegal V, et al; NMHS collaborators group. National Mental Health Survey of India, 2015-16: Prevalence, patterns and outcomes. Bengaluru, National Institute of Mental Health and Neuro Sciences, NIMHANS. 2016; Publication No. 129, 2016

20 Hawryluck L, Gold WL, Robinson S, Pogorski S, Galea S, Styra R. SARS control and psychological effects of quarantine, Toronto, Canada. Emerg Infect Dis 2004;10(7):1206-1212 